\title{
Fabrication and characterization of inorganic-organic hybrid solar cells based on $\mathrm{CulnS}_{2}$
}

\author{
Akihiro TAKEDA, ${ }^{\dagger}$ Takeo OKU,${ }^{\ddagger}$ Atsushi SUZUKI, Kenji KIKUCHI and Shiomi KIKUCHI \\ Department of Materials Science, The University of Shiga Prefecture, 2500 Hassaka, Hikone, Shiga 522-8533
}

\begin{abstract}
Chalcopyrite compounds/fullerene solar cells based on copper-indium-disulphide and $\mathrm{C}_{60}$ were produced. Two-types of devices with heterojunction and bulk heterojunction structures were examined and characterized. The bulk heterojunction structure provided better efficiency compared to that of the heterojunction structure. Nanostructures of the solar cells were confirmed as mixed nanocrystals by transmission electron microscopy. A photovoltaic mechanism of the present solar cells was discussed on the basis of the experimental results.
\end{abstract}

(C2009 The Ceramic Society of Japan. All rights reserved.

Key-words : CulnS $2, \mathrm{C}_{60}$, Solar cell

[Received May 12, 2009; Accepted August 20, 2009]

\section{Introduction}

Silicon solar cells are mainstream in the world because of their high performance, long life and high reliability. However, silicon solar cells have some problems. For example, silicon raw materials are close to the supply limit, and the production energy is high due to the complicated process, and energy payback time is long. Therefore, development of new solar cells instead of silicon solar cells is mandatory.

I-III-VI group compounds called chalcopyrite are expected as next generation solar cell materials. Chalcopyrite compounds have advantages of high optical absorption and high resistivity to cosmic rays compared to conventional silicon solar cells. In addition, they have a band structure of direct transition, which shows high quantum efficiency. Therefore, development of chalcopyrite compounds solar cells have been performed. ${ }^{1), 2)}$ Although CdS is used for most of the chalcopyrite solar cells to obtain high efficiency, development of the Cd-free solar cells has continued because of the poisonous influence of $\mathrm{Cd}$ on the environment.

The purpose of the present work is to investigate the Cd-free inorganic-organic hybrid solar cells with $\mathrm{CuInS}_{2}$ (CIS) for p-type semiconductor and with $\mathrm{C}_{60}$ for an organic n-type semiconductor. CIS is one of the representative chalcopyrite compounds, and $\mathrm{C}_{60}$ is suitable for n-type semiconductors due to strong electron affinity.

\section{Experimental procedures}

CIS solution for p-type semiconductors were produced by dissolving $\mathrm{CuI}$ (Sigma-Aldrich Corp., 99.99\%) and $\mathrm{InCl}_{3}$ (SigmaAldrich Corp., $99.99 \%)$ in a mixture of triphenylphosphite $(1 \mathrm{ml})$ (Sigma-Aldrich Corp., 97\%) and acetonitrile (2 ml) (Nacalai Tesque, Inc., 99.5\%), dropping bis(trimethylsilyl)sulfide (Tokyo Chemical Industry Co., Ltd., > 95\%). ${ }^{3)}$ The solution for n-type semiconductors was prepared by dissolving $\mathrm{C}_{60}$ (Material Technologies Research Ltd., 99.98\%) in $o$-dichlorobenzene (Nacalai Tesque, Inc., 99\%). A thin layer of polyethylenedioxythiophene doped with polystyrene-sulfuric acid (PEDOT:PSS) (Sigma-

\footnotetext{
Corresponding author: A. Takeda; E-mail: zi22atakeda@ec.usp. ac.jp

‡ Corresponding author: T. Oku; E-mail: oku@mat.usp.ac.jp
}

Aldrich Corp.) was spin-coated on a pre-cleaned fluorine dope tin oxide (FTO) glass plates (Asahi Glass, 9.3 $\Omega / \square$ ). Then, semiconductor layers were prepared on a PEDOT:PSS layer by spin coating. After annealing at $120^{\circ} \mathrm{C}$ for $10 \mathrm{~min}$ in $\mathrm{N}_{2}$ atmosphere, aluminum ( $\mathrm{Al})$ metal contacts were evaporated as a top electrode, and annealed at $250^{\circ} \mathrm{C}$ for $20 \mathrm{~min}$ in $\mathrm{N}_{2}$ atmosphere. ${ }^{4), 5)}$ A schematic diagram of the present solar cells is shown in Fig. 1.

The current density-voltage $(\mathrm{J}-\mathrm{V})$ characteristics (Hokuto Denko Corp., HSV-100) of the solar cells were measured both in the dark and under illumination at $100 \mathrm{~mW} / \mathrm{cm}^{2}$ by using an AM 1.5 solar simulator (San-ei Electric, XES-301S). The solar cells were illuminated through the side of the FTO substrates, and the illuminated area is $0.16 \mathrm{~cm}^{2}$. Optical absorption of the solar cells was measured by UV-visible spectroscopy (Hitachi, Ltd., U-4100). Microstructures of semiconductor layers of the CIS: $\mathrm{C}_{60}$ bulk heterojunction were investigated by transmission electron microscopy (TEM, Hitachi, Ltd., H-8100) and X-ray diffraction (XRD, Philips X' Pert-MPD System).

\section{Results and discussion}

Measured current density-voltage ( $\mathrm{J}-\mathrm{V})$ characteristics of both $\mathrm{CIS} / \mathrm{C}_{60}$ heterojunction structure and $\mathrm{CIS}: \mathrm{C}_{60}$ bulk heterojunction structures under illumination are shown in Fig. 2. Each structure shows characteristic curves for open circuit voltage and short circuit current.

Measured parameters of these solar cells are summarized in Table 1. A solar cell with CIS: $\mathrm{C}_{60}$ bulk heterojunction structure (a)

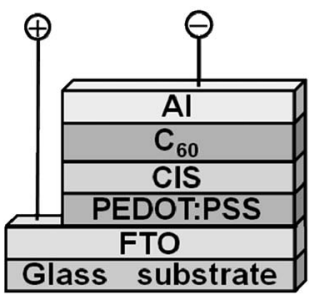

(b)

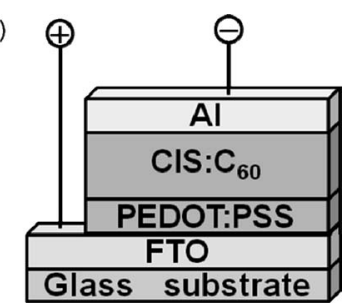

Fig. 1. Device structures of (a) heterojunction and (b) bulk heterojunction solar cells. 


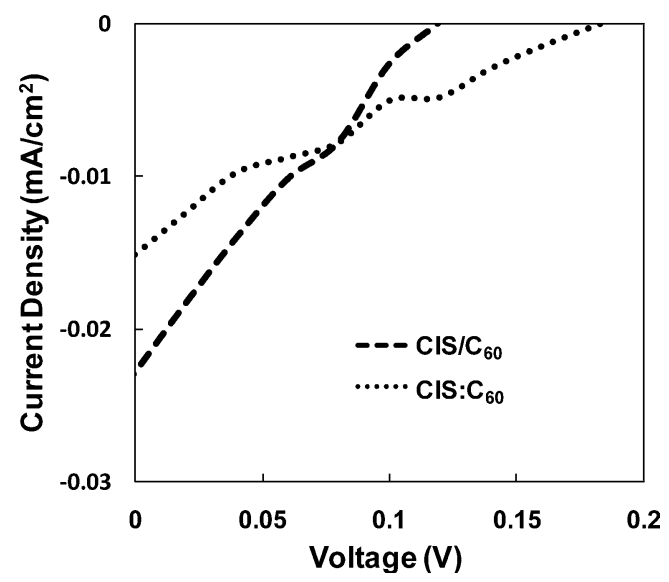

Fig. 2. Current density-voltage (J-V) characteristic of CIS/ $\mathrm{C}_{60}$ heterojunction solar cells and CIS: $\mathrm{C}_{60}$ bulk heterojunction solar cells under illumination.

Table 1. Measured Parameters of the Solar Cells

\begin{tabular}{cccccc}
\hline Sample & $\mathrm{E}_{\mathrm{ff}}(\%)$ & $\mathrm{FF}$ & $\mathrm{V}_{\mathrm{oc}}(\mathrm{V})$ & $\mathrm{J}_{\mathrm{sc}}\left(\mathrm{mA} / \mathrm{cm}^{2}\right)$ & $\begin{array}{c}\lambda_{\text {peak }}(\mathrm{nm}) \\
\text { Energy }(\mathrm{eV})\end{array}$ \\
\hline CIS/C $_{60}$ & $6.2 \times 10^{-4}$ & 0.23 & 0.12 & 0.023 & $\begin{array}{c}392,452 \\
3.2,2.7\end{array}$ \\
& & & & & $418,468,529,613,723$ \\
CIS:C 60 & $8.0 \times 10^{-4}$ & 0.28 & 0.18 & 0.016 & $3.0,2.6,2.3,2.0,1.7$ \\
\hline
\end{tabular}

provided power convergent efficiency $(\eta)$ of $8.0 \times 10^{-4} \%$, fill factor $(\mathrm{FF})$ of 0.28 and open-circuit voltage $\left(\mathrm{V}_{\mathrm{oc}}\right)$ of $0.18 \mathrm{~V}$, which is better than those of a CIS/ $\mathrm{C}_{60}$ heterojunction device. On the other hand, the CIS/ $\mathrm{C}_{60}$ heterojunction structure showed a higher short-current density $\left(\mathrm{J}_{\mathrm{sc}}\right)$ of $0.023 \mathrm{~V}$. The $\mathrm{p}-\mathrm{n}$ interfaces, which are photoelectron conversion areas were increased by using blend structures of p-type and n-type semiconductors. A small increase of conversion efficiency was observed by dispersion of p-type and n-type semiconductors.

Figure 3 is a measured optical absorption of the solar cells based on CIS. These solar cells show a wide optical absorption range from 400 to $800 \mathrm{~nm}$, and the heterojunction solar cell show a higher optical absorption range from $350 \mathrm{~nm}$ to $550 \mathrm{~nm}$ than that of the bulk heterojunction. Since the FTO substrate was set as an incident side, the optical absorption of the CIS layer was high for the heterojunction structure. On the other hand, optical absorption of the bulk heterojunction would be lower compared to that of the heterojunction structure because $\mathrm{C}_{60}$ were mixed with the CIS layer.

An X-ray diffraction pattern of CIS: $\mathrm{C}_{60}$ bulk heterojunction is shown in Fig. 4. Several diffraction peaks are observed, which correspond to 112, 204 of CIS and 111, 220, 311, 222, 422, 511 of $\mathrm{C}_{60}{ }^{1,1,6)}$ The average particle sizes of $\mathrm{CuInS}_{2}$ and $\mathrm{C}_{60}$ were calculated from Scherrer's formula to be $5 \mathrm{~nm}$ and $13 \mathrm{~nm}$, respectively.

Figure 5(a) is a TEM image of CIS, and many CIS particles are observed. Figure 5(b) is an electron diffraction pattern of CIS. Debye-Scherrer rings are observed in the diffraction pattern, which shows crystallite structures of CIS particles.

An interfacial structure of CIS and $\mathrm{C}_{60}$ was observed by TEM as shown in Fig. 6. Filtered Fourier transform of the HREM image of CIS: $\mathrm{C}_{60}$ bulk heterojunction layer is shown in Fig. 6(a). Figure $6(\mathrm{~b})$ is an inverse Fourier transform of (a), and arrows

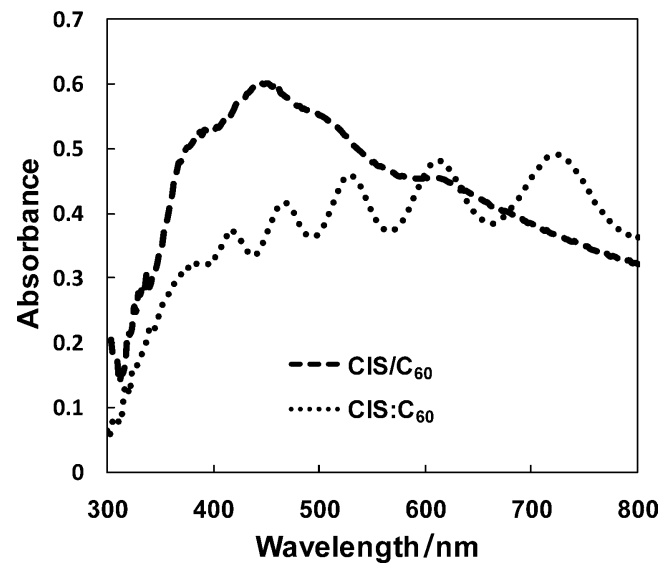

Fig. 3. Optical absorption spectra of heterojunction and bulk heterojunction solar cells.

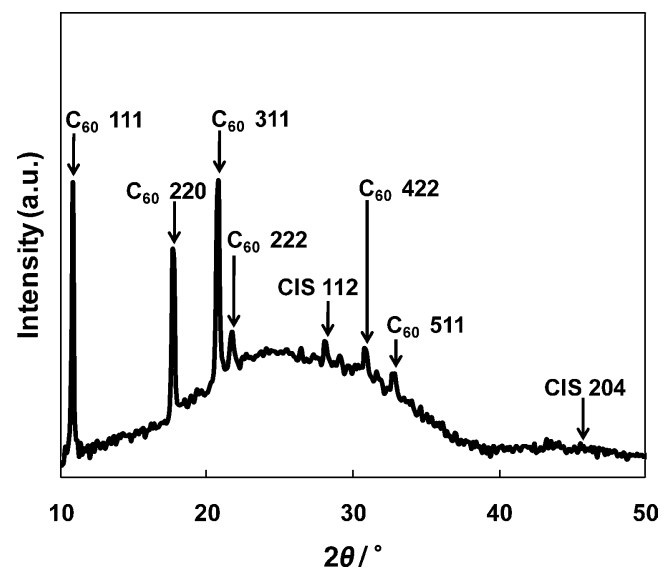

Fig. 4. X-ray diffraction pattern of CIS: $\mathrm{C}_{60}$ thin film.
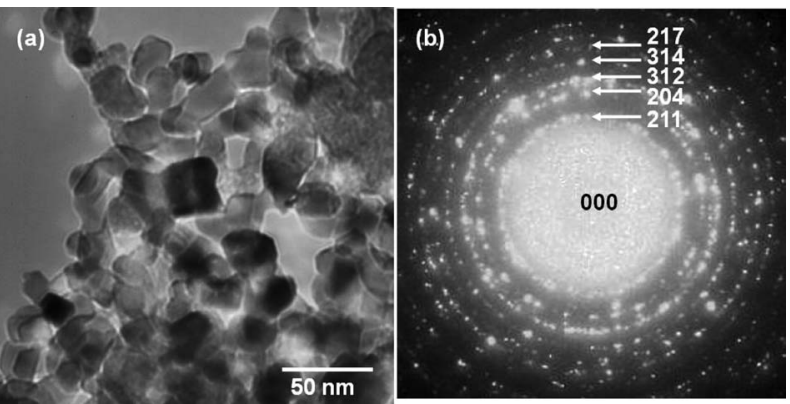

Fig. 5. TEM image of CIS nanoparticles and electron diffraction pattern of CIS.

show the interface of CIS and $\mathrm{C}_{60}$. Lattice fringes of $\{101\}$ of CIS and $\{111\}$ of $\mathrm{C}_{60}$ were observed. The enlarged image of a part of $\mathrm{C}_{60}$ in (b) is shown in Fig 6(c). Arrangements of $\mathrm{C}_{60}$ molecules are observed in the image. CIS and $\mathrm{C}_{60}$ have size distribution, and the crystal sizes of them observed in the TEM image are larger compared to the average sizes.

Optimization of the nanocomposite structure with CIS and $\mathrm{C}_{60}$ would increase the efficiencies of the bulk heterojunction solar cell. From the present TEM observation, CIS and $\mathrm{C}_{60}$ were not mixed in a molecular scale. If the mixture structure of CIS and 
$\mathrm{C}_{60}$ is improved to a nanoscale, it is believed that the area of the p-n junction interface is increased, and the efficiency would be improved. In addition, it is important to search the most suitable mixture ratio of the p-type and n-type semiconductors for bulk heterojunction solar cells.

An energy level diagram of $\mathrm{CIS} / \mathrm{C}_{60}$ solar cells is summarized as shown in Fig. 7. Previously reported values were used for the energy levels of the figures by adjusting them to the present work. ${ }^{7-9)}$ When light is incident from the FTO side, excitation by the light absorption happens in the p-n interface, and electrons and holes are produced by charge separation. Carriers would

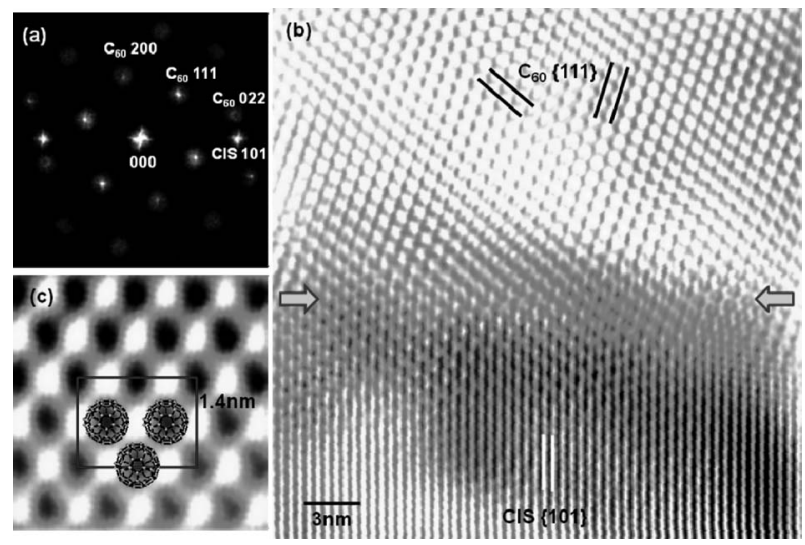

Fig. 6. (a) Filtered fourier transform of HREM image of CIS: $\mathrm{C}_{60}$ bulk heterojunction layer. (b) Inverse Fourier transform of (a). (c) Enlarged image of a part of $\mathrm{C}_{60}$ in (b).

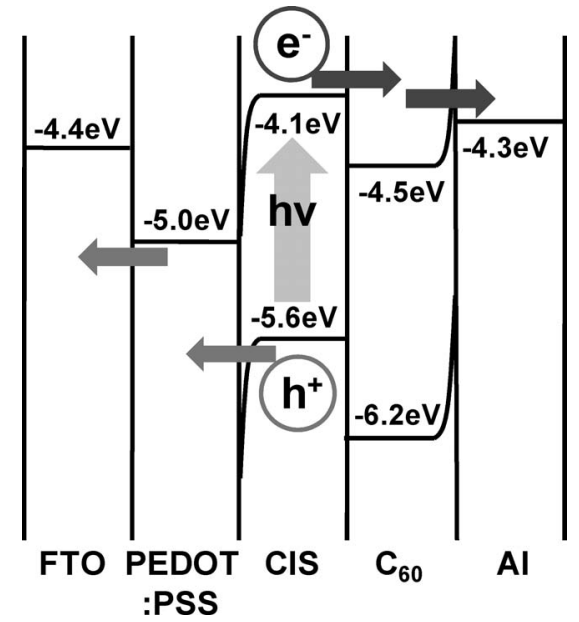

Fig. 7. Energy level diagram of CIS: $\mathrm{C}_{60}$ solar cells. transport from $-4.5 \mathrm{eV}$ to $-4.3 \mathrm{eV}$ by hopping conduction. Improvement of the present bulk heterojunction solar cells would be possible by the introduction of a buffer layer, change of annealing conditions, and the improvement of the microstructure is also necessary to obtain high efficiency.

The evaporation method provided high quality thin films, but a high vacuum and high temperature process are necessary. Although CISCuT method is a productive process, it requires a high temperature process. ${ }^{10)}$ On the other hand, the present spin coating method is simpler compared to the other formation methods. In addition, we can apply the spin coating method to plastic substrates without high vacuum and high temperature processes.

\section{Conclusions}

Chalcopyrite/fullerene solar cells were fabricated and characterized. A device of bulk heterojunction structure based on $\mathrm{CuInS}_{2}$ and $\mathrm{C}_{60}$ provided $\eta$ of $8.0 \times 10^{-4} \%$, FF of 0.28 , Voc of $0.18 \mathrm{~V}$, which is better than those of the heterojunction structure. The present solar cells showed a high optical absorption in the range of $300 \mathrm{~nm}$ to $800 \mathrm{~nm}$. Microstructures of the solar cells were observed by TEM and XRD, which indicated average particle sizes of $\mathrm{CuInS}_{2}$ and $\mathrm{C}_{60}$ of $5 \mathrm{~nm}$ and $13 \mathrm{~nm}$, respectively. A carrier transfer mechanism was discussed by the energy level diagram.

\section{References}

1) Y. Qi, K. Tang, S. Zeng and W. Zhou, Microporous Mesoporous Mater., 114, 395-400 (2008).

2) Y. Chen, X. He, X. Zhao, M. Song and X. Gu, Mater. Sci. Eng., B 139, 88-94 (2007).

3) E. Arici, N. S. Sariciftci and D. Meissner, Adv. Funct. Mater., 13, 1-7 (2003).

4) T. Oku, S. Nagaoka, A. Suzuki, K. Kikuchi, Y. Hayashi, H. Sakuragi and T. Soga, J. Ceramic Processing Res., 9, 549-552 (2008).

5) S. K. Kim, W. J. Jeong, G. C. Park, Y. G. Back, Y. G. Jeong and Y. T. Yoo, Synthetic Metals, 71, 1747-1748 (1995).

6) J. Feng, J. Han and X. Zhao, Prog. Organic Coatings, 64, 268-273 (2009).

7) T. Oku, N. Kakuta, A. Kawashima, K. Nomura, R. Motoyoshi, A. Suzuki, K. Kikuchi and G. Kinoshita, Mater. Trans., 49, 2457-2460 (2008).

8) C. Voz, J. Puigdollers, S. Cheylan, M. Fonrodona, M. Stella, J. Andreu and R. Alcubilla, Thin Solid Films, 515, 7675-7678 (2007).

9) Y. Berredjem, N. Karst, L. Cattin, A. Lakhdar-Toumi, A. Godoy, G. Soto, F. Diaz, M. A. Del Valle, M. Morsli, A. Drici, A. Boulmokh, A. H. Gheid, A. Khelil and J. C. Bernède, Dyes and Pigments, 78, 148-156 (2008).

10) M. Winkler, J. Griesche, I. Konovalov, J. Penndorf, J. Wienke and O. Tober, Solar Energy, 77, 705-716 (2004). 